\title{
Lambl's Excrescences and Stroke: A Scoping Study
}

Pramod Theetha Kariyanna $^{1}$, Apoorva Jayarangaiah ${ }^{2 *}$, Chandra Rednam ${ }^{3 *}$, Sudhanva Hegde ${ }^{1}$, Jonathan D. Marmur ${ }^{1}$, Haroon Kamran $^{1}$, Perry Wengrofsky ${ }^{1}$, Jason Green ${ }^{1}$, Rodaina Ahmed ${ }^{1}$ and Samy I. McFarlane ${ }^{1^{*}}$

${ }^{1}$ Divisions of Cardiovascular Disease, and Endocrinology, Department of Internal Medicine, State University of New York, Downstate Medical Center, Brooklyn, New York, 11203, USA

${ }^{2}$ Department of Internal Medicine, Wake Forest University, Baptist Health System, Winston-Salem, North Carolina, 27157, USA

${ }^{3}$ Division of Cardiology, Department of Internal Medicine, Veterans Affairs New York Harbor Healthcare System-Brooklyn, Brooklyn, New York, 11209, USA

\begin{abstract}
Stroke / Cerebrovascular accident (CVA) is a leading cause of morbidity and mortality in the world. Ischemic stroke accounts for $87 \%$ of the cases, $14-30 \%$ of which is attributed to cardio-embolic stroke. Lambl's excrescences (LE) were first described in 1856 by a Bohemian physician- VilemDusanLambl and is considered a rare cause of cardioembolic stroke subtype. LE are branched filiform structures with undulating movements, $1 \times 4-10 \mathrm{~mm}$ in size that are usually found on aortic and mitral valves. An atheroma from LE or LE fragments per se may embolize to cerebrovascular arterial territory causing stroke. Multiple isolated cases of stroke associated with LE have been reported in the literature. We hereby report a scoping study of the findings associated with such cases. A total of 27 cases were identified after various scientific databases including PubMed and Google scholar were searched with keywords "lambl's excrescences, stroke, cerebrovascular accidents". Data from these cases were tabulated and analyzed. The mean age at presentation was $51 \pm 14.2( \pm \mathrm{SD})$ years with $55 \%$ of patient younger than 55 years of age. $56 \%$ of cases were males. Transesophageal echocardiogram was more effective in detecting LE when compared to transthoracic echocardiogram. LE were most often found on aortic valve and LE related stroke was most often noted in middle cerebral artery territory. Recurrent stroke was reported in $30 \%$. Management of these cases was highly variable and likely derived from individual experience as LE management guidelines are largely lacking. Single and dual antiplatelet therapy, anticoagulation and valvularsurgery were among the various management strategies employed. We recommend dual antiplatelet after the first episode of CVA related to LE and an antiplatelet in combination with anticoagulation after the second CVA attributed to LE. Also it is reasonable to offer valve replacement after second CVA related to LE as the reccurence rate of CVA is high. Due to rarity in LE reporting and its management a shared decision making has to be made depending on the clinical status of the patient.

The formation of a worldwide registry for LE using standardized reporting criteria for the diagnosis with or without incident stroke, would help establish guidelines for the diagnosis and management of this rare, yet serious disease with increased risk of morbidity and mortality.
\end{abstract}

\section{Publication History:}

Received: July 24, 2018

Accepted: October 18, 2018

Published: October 20, 2018

\section{Keywords:}

Stroke, Neurofeedback, Auditory, Upper extremity, Motor imagery

\section{Introduction}

Cerebrovascular accident (CVA) is a known cause of significant morbidity and mortality in the United States [1]. Ischemic stroke accounts for majority of strokes [2]. Cardio-embolic strokes account for nearly $14-30 \%$ of ischemic stroke and are often associated with recurrence and high mortality [3]. Lambl's excrescences (LE) (Figure 1) though often reported in transesophageal echocardiography of patients who suffered stroke it is not clear if they are bystanders or the cardio-embolic source of such stoke [4]. Multiple isolated case reports of stroke where LE has been attributed as the cause of stroke have been reported. Guidelines regarding management of LE in the setting of stroke are largely lacking. We here undertake the first scoping study of cases of stroke associated with LE reported to understand the clinical profile of these patients, imaging studies and management that were employed, recurrent rates and mortality.

\section{Methods}

On 28th January 2018, a systematic search was conducted using Pubmed, Google Scholar, CINAHL, Cochrane CENTRAL and Web of Science databases (Figure 2). Studies listing the keywords "lambl's excrescences, stroke, cerebrovascular accidents" were used to identify cases of stroke associated with LE. No specific duration was chosen during search.The reference list of each report was also checked for additional cases. All cases were reviewed in detail. Data reviewed

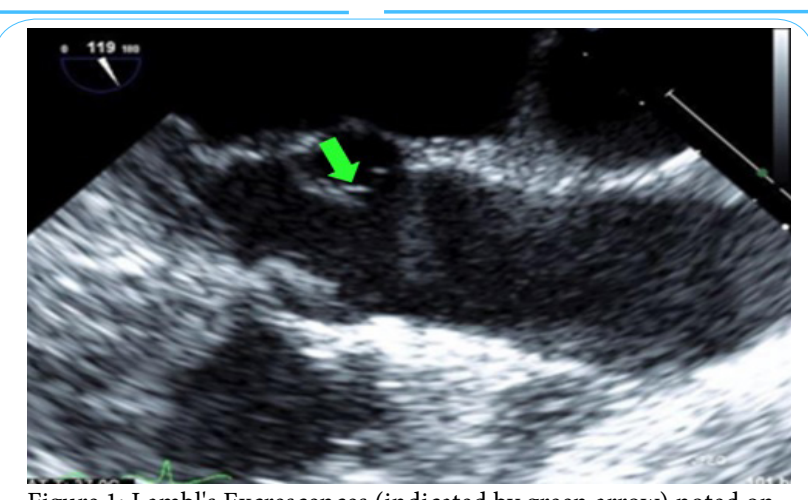

Figure 1: Lambl's Excrescences (indicated by green arrow) noted on aortic valve as noted in transesophageal echocardiography.

"Corresponding Author: Prof. Samy I. McFarlane, Divisions of Cardiovascular Disease, and Endocrinology, Department of Internal Medicine, State University of New York, Downstate Medical Center, Brooklyn, New York,11203, USA, Tel: 718270-6707, Fax: 718-270-4488; E-mail: smcfarlane@downstate.edu

\section{"Equal contribution}

Citation: Kariyanna PT, Jayarangaiah A, Rednam C, Hegde S, Marmur JD, et al. (2018) Lambl's Excrescences and Stroke: A Scoping Study. Int J Clin Res Trials 3: 127. doi: https://doi.org/10.15344/2456-8007/2018/127

Copyright: (C) 2018 Kariyanna et al. This is an open-access article distributed under the terms of the Creative Commons Attribution License, which permits unrestricted use, distribution, and reproduction in any medium, provided the original author and source are credited. 
Citation: Kariyanna PT, Jayarangaiah A, Rednam C, Hegde S, Marmur JD, et al. (2018) Lambl's Excrescences and Stroke: A Scoping Study. Int J Clin Res Trials 3:

Key words used for search: Lambl's excrescences, stroke, cerebrovascular accidents

Search conducted in: PubMed, Google Scholar, CINAHL, Cochrane CENTRAL and Web of Science databases

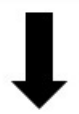

A total of 162 papers appeared on the search

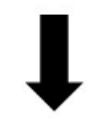

27 papers in English literature which reported cases of LE related CVA were chosen for the scoping study

Figure 2: Flow chart summarizing the method of selection of cases for the study.

included demographic data, CV risk factors, electrocardiography (ECG) findings, transthoracic echocardiography (TTE), transesophageal echocardiography (TEE), computed tomography of the head, recurrence of stroke, management of LE and death (Figure $3)$.

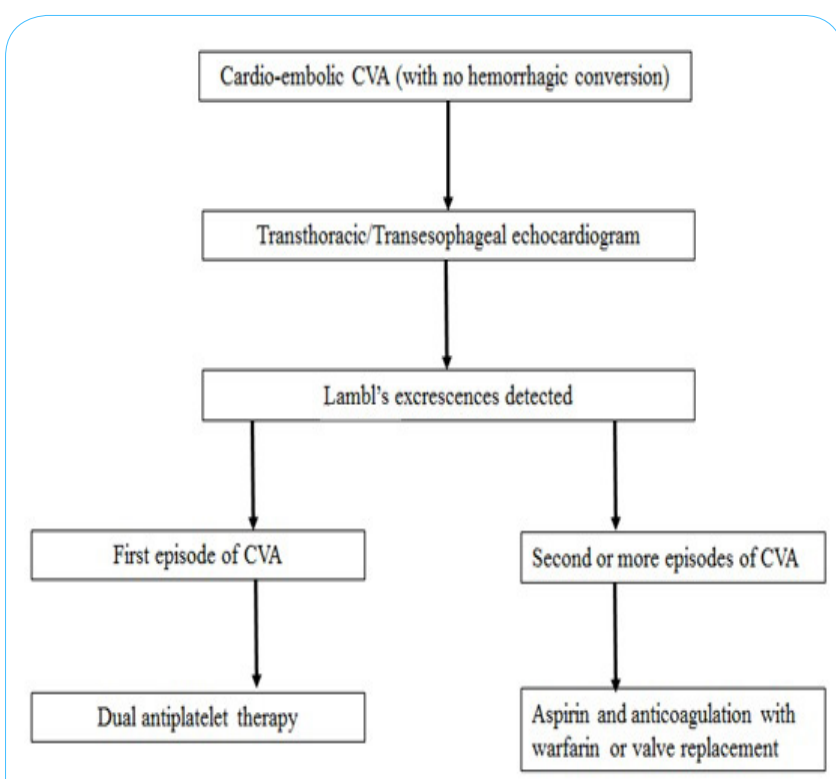

Figure 3: Recommendations for the management of LE.

\section{Results}

A total of 27 cases were identified (Table 1) [5- 27]. The patients were in the age group of 25 to 78 years and the mean age was 51 \pm 14.2 years, median age was 53 years and $44 \%$ of the cases were younger than 50 years of age and $55.5 \%$ of cases were younger than 55 years. $56 \%$ of the cases were reported in males and $44 \%$ in females. Prevalence of cerebrovascular risk factors and co-morbidities in the population was as follows: hypertension $29.63 \%$, diabetes $18.52 \%$, history of stroke $14.81 \%$, smoking $14.81 \%$, alcohol abuse $11.11 \%$, chronic obstructive pulmonary disease (COPD) $7.41 \%$, history of transient ischemic attack $3.70 \%$, history of coronary artery disease (CAD) $3.70 \%$, obstructive sleep apnea $3.70 \%$, deep vein thrombosis $3.70 \%$ and cocaine use $3.70 \%$. Majority of patients presented with dysarthria/aphasia (51.85\%) and hemiparesis (37.04\%); other presenting complaints have been tabulated (Table 2).

TTE was reported in 14 cases, of which 6 cases (42.85\%) reported LE ( 2 on aortic valve, 4 on mitral valve), 1 case $(7.14 \%)$ raised the suspicion for LE and no LE was detected on TTE in 7 cases (50\%) all of whom were noted to have LE on TEE. TEE was reported in 22 cases of whom LE was noted on aortic valve in $82 \%$, on mitral valve in $14 \%$ and pulmonary valve in $4 \%$. A total of 26 cases reported the valve of LE origin which was aortic valve $73 \%$, mitral valve $23 \%$ and pulmonary valve $4 \% .25$ cases reported the number of LE of which $64 \%$ of cases reported a single LE and remaining $36 \%$ of cases reported more than one LE as visualized in TEE or TTE (Table 3). Middle cerebral artery (MCA) territory was most commonly affected (Table 1). 30\% reported recurrence. Management of stroke secondary to LE (Table 1 and Table 4). No mortality was reported.

\section{Discussion}

Cerebrovascular accidents (CVA) also known as stroke is a significant cause of morbidity and mortality in the United States and is the fifth leading cause of death [1]. About 800,000 cases of stroke are reported annually of which about 600 are new strokes [1]. About $87 \%$ of CVA are ischemic in nature [28-31]. When compared to firstmultiple isolated cases of LE association with stroke and recurrent stroke have been reported. Also cases of thromboembolism into coronary artery [32], renal artery [33] and popliteal artery [34] have been reported. LE usually develop at the site of valvular closure where endothelial damage happens secondary to valve wear and tear forces [35]. LE on gross examination are filiform projections with narrow base, that are $1 \mathrm{X} 4-10 \mathrm{~mm}$ in size and often branches are noted. LE most commonly noted on aortic and mitral valves $[18,35]$. Potion of LE may detach to cause embolisation or an atheroma originating on LE may embolize to cause stroke $[18,36]$. Transesophageal echocardiogram is more specific in detection of LE as compared to transesophageal echocardiogram [18, 36, 37]. Differential diagnosis for LE include i) papillary elastomers which has short broad stalk, jelly like homogeneous masses that appear in endocardium areas of valves where there is less wear and tear, ii) infective endocarditis, iii) artifact, iv) thrombus, v) redundant leaflet of a valve, and vi) intimal flap of aortic dissection [11]. Computed tomography is helpful in differentiating LE from its differentials $[18,36]$. LE was noted to be present in $22 \%$ of patients on whom transesophageal echocardiogram was performed following stroke [4]. Despite the high prevalence of LE in patients who had stroke it is unclear if LE is the etiology or an incidental finding in these patients [38].

Recent trends suggest age at relatively younger age and in 2005 age at stroke was 69.2 years with $12.9 \%$ of patients under age 55 years [39]. The mean age at stroke in our study was $51 \pm 14.2$ years and about $55 \%$ of patients were younger than 55 years of age. Compared to statistics from 2005 [17] our patients were relatively younger likely due to cardio-embolic source of stroke. MCA territory was most commonly affected territory. TTE was not effective in detecting LE and missed LE in $50 \%$ of the cases and LE in these. Thus it can be concluded that TEE is superior to TTE in diagnosing LE. LE originated from aortic valve most commonly followed by mitral and pulmonary valve. Recurrent stroke was reported in $30 \%$ of cases. Though no mortality was not reported at the time of publication of these cases it is not clear if stroke secondary to LE led to mortality in any of the patients. Management strategy employed varied widely likely based on individual experience as large. 
Citation: Kariyanna PT, Jayarangaiah A, Rednam C, Hegde S, Marmur JD, et al. (2018) Lambl's Excrescences and Stroke: A Scoping Study. Int J Clin Res Trials 3: 127. doi: https://doi.org/10.15344/2456-8007/2018/127

Page 3 of 5

\begin{tabular}{|c|c|c|c|c|c|c|c|}
\hline & & Aspirin & $\begin{array}{l}\text { Second } \\
\text { antiplatelet }\end{array}$ & Statins & Anticoagulation & $\begin{array}{l}\text { Valvular } \\
\text { surgery }\end{array}$ & \\
\hline 1. & $\begin{array}{l}\text { 1997, Nighoghossianet } \\
\text { al. [5] }\end{array}$ & LMCA & & & & $\checkmark$ & \\
\hline 2. & $\begin{array}{l}\text { 1997, Nighoghossian } \\
\text { et al. [5] }\end{array}$ & LMCA & & & & & $\checkmark$ \\
\hline 3. & $\begin{array}{l}\text { 1997, Nighoghossianet } \\
\text { al. [5] }\end{array}$ & LMCA & & & & $\checkmark$ & $\checkmark$, after recurrent stroke \\
\hline 4. & 1999, Vorgos et al. [6] & RMCA & & & & & \\
\hline 5. & $\begin{array}{l}\text { 2003, Aggarwal et } \\
\text { al. [7] }\end{array}$ & RMCA & & & & & $\checkmark$, after recurrent stroke \\
\hline 6. & $\begin{array}{l}\text { 2006, Siles Rubio et } \\
\text { al. [8] }\end{array}$ & LMCA & $\checkmark$ & & & & \\
\hline 7. & 2007, Aziz et al. [9] & LMCA & & & & & $\checkmark$ \\
\hline 8. & 2007, Wolf et al. [10] & LMCA & $\checkmark$ & & & & \\
\hline 9. & $\begin{array}{l}\text { 2010, Kalavakunta et } \\
\text { al. [11] }\end{array}$ & $\begin{array}{l}\text { Bilateral B/L cerebral } \\
\text { hemispheres }\end{array}$ & & & & $\checkmark$ & \\
\hline 10. & 2011, Raju et al. [12] & Right posterior circulation & $\checkmark$ & & & & \\
\hline 11. & $\begin{array}{l}\text { 2011, Manolakis et } \\
\text { al. [13] }\end{array}$ & $\begin{array}{l}\text { Right frontal and right } \\
\text { cerebellar }\end{array}$ & & & & $\checkmark$ & $\checkmark$ \\
\hline 12. & 2012, Liu et al. [14] & Left cerebellar hemisphere & $\checkmark$ & & & & \\
\hline 13. & 2012, Liu et al. [14] & $\begin{array}{l}\text { Corpus Callosum, right } \\
\text { Temporal-Parietal lobe }\end{array}$ & & & & & $\checkmark$ \\
\hline 14. & $\begin{array}{l}\text { 2013, Al-Ansari et } \\
\text { al. [15] }\end{array}$ & $\begin{array}{l}\text { Right Frontoparietal, left } \\
\text { Thalamus }\end{array}$ & & & & & $\checkmark$ \\
\hline 15. & 2013, Wu et al. [16] & $\begin{array}{l}\text { Left posterior cerebral } \\
\text { artery }\end{array}$ & & & & $\checkmark$ & \\
\hline 16. & $\begin{array}{l}\text { 2014, Veloria et al. } \\
{[17]}\end{array}$ & $\begin{array}{l}\text { Left central pons and } \\
\text { corpus callosum }\end{array}$ & & & & $\checkmark$ & $\checkmark$ \\
\hline 17. & $\begin{array}{l}\text { 2014, Yacoub et al. } \\
{[18]}\end{array}$ & LMCA & $\checkmark$ & & $\checkmark$ & & \\
\hline 18. & $\begin{array}{l}\text { 2015, Kitchool et al. } \\
\text { (19) }\end{array}$ & $\begin{array}{l}\text { Right thalamus, posterior } \\
\text { capsule }\end{array}$ & $\checkmark$ & $\checkmark$ & & & \\
\hline 19. & 2015, Chu et al. [20] & $\begin{array}{l}\text { Right Corona radiata, } \\
\text { Centrum Semiovale, right } \\
\text { cerebral hemisphere }\end{array}$ & $\checkmark$ & $\checkmark$ & & & \\
\hline 20. & 2015, Villella et al. [21] & Left optic artery & $\checkmark$ & & & & \\
\hline 21. & $\begin{array}{l}\text { 2015, Dumitrascu et } \\
\text { al. [22] }\end{array}$ & $\begin{array}{l}\text { Left parietal lobe, bilateral } \\
\text { centrum semiovale, right } \\
\text { occipital }\end{array}$ & $\checkmark$ & $\checkmark$ & & & \\
\hline 22. & $\begin{array}{l}\text { 2015, Davogustto et } \\
\text { al. [23] }\end{array}$ & Left centrum Semiovale & $\checkmark$ & & & & \\
\hline 23. & $\begin{array}{l}\text { 2016, Kamran et al. } \\
{[24]}\end{array}$ & LMCA & $\checkmark$ & & $\checkmark$ & & \\
\hline 24. & 2016, Jo et al. [25] & RMCA & $\checkmark$ & $\checkmark$ & & & \\
\hline 25. & 2016, Jo et al. [25] & LMCA & & & $\checkmark$ & & \\
\hline 26. & $\begin{array}{l}\text { 2017, Meireleset al. } \\
{[26]}\end{array}$ & $\begin{array}{l}\text { Right occipital Lobe, } \\
\text { cerebellar hemispheres }\end{array}$ & & & $\checkmark$ & & \\
\hline 27. & $\begin{array}{l}\text { 2017, Vlacancich et } \\
\text { al. [27] }\end{array}$ & Right precentral gyrus & $\checkmark$ & $\checkmark$ & & & \\
\hline
\end{tabular}

Table 1: Cases of LE included in the study. 
Citation: Kariyanna PT, Jayarangaiah A, Rednam C, Hegde S, Marmur JD, et al. (2018) Lambl's Excrescences and Stroke: A Scoping Study. Int J Clin Res Trials 3: 127. doi: https://doi.org/10.15344/2456-8007/2018/127

Page 4 of 5

\begin{tabular}{|c|c|c|c|}
\hline $\begin{array}{l}\text { Serial } \\
\text { number }\end{array}$ & Year, author & $\begin{array}{l}\text { Transthoracic } \\
\text { echocardiogram }\end{array}$ & $\begin{array}{l}\text { Transesophageal } \\
\text { echocardiogram }\end{array}$ \\
\hline 1. & $\begin{array}{l}1997, \\
\text { Nighoghossian et } \\
\text { al. [5] }\end{array}$ & Normal & LE on mitral valve \\
\hline 2. & $\begin{array}{l}1997, \\
\text { Nighoghossian et } \\
\text { al. [5] }\end{array}$ & $\begin{array}{l}\text { LE on mitral } \\
\text { valve }\end{array}$ & - \\
\hline 3. & $\begin{array}{l}1997, \\
\text { Nighoghossianet } \\
\text { al. [5] }\end{array}$ & $\begin{array}{l}\text { LE on mitral } \\
\text { valve }\end{array}$ & - \\
\hline 4. & $\begin{array}{l}\text { 1999, Vorgos et } \\
\text { al. [6] }\end{array}$ & - & $\begin{array}{l}4 \mathrm{LE} \text { on Pulmonary } \\
\text { valves }\end{array}$ \\
\hline 5. & $\begin{array}{l}\text { 2003, Aggarwal et } \\
\text { al. [7] }\end{array}$ & $\begin{array}{l}\text { LE on aortic } \\
\text { valve }\end{array}$ & - \\
\hline 6. & $\begin{array}{l}\text { 2006, Siles Rubio } \\
\text { et al. [8] }\end{array}$ & - & LE on Aortic valve \\
\hline 7. & 2007, Aziz et al. [9] & - & LE on Aortic valve \\
\hline 8. & $\begin{array}{l}\text { 2007, Wolf et al. } \\
{[10]}\end{array}$ & - & LE on Aortic valve \\
\hline 9. & $\begin{array}{l}\text { 2010, Kalavakunta } \\
\text { et al. [11] }\end{array}$ & - & LE on Aortic valve \\
\hline 10. & $\begin{array}{l}\text { 2011, Raju et al. } \\
{[12]}\end{array}$ & $\begin{array}{l}\text { Suspicious of } \\
\text { Aortic Valve } \\
\text { mass }\end{array}$ & LE on Aortic valve \\
\hline 11. & $\begin{array}{l}\text { 2011, Manolakis et } \\
\text { al. [13] }\end{array}$ & - & LE on Aortic Valve \\
\hline 12. & 2012, Liu et al. [14] & - & LE on Aortic Valve \\
\hline 13. & 2012, Liu et al. [14] & - & LE on Aortic Valve \\
\hline 14. & $\begin{array}{l}\text { 2013, Al-Ansari et } \\
\text { al. [15] }\end{array}$ & $\begin{array}{l}\text { LE on Mitral } \\
\text { Valve }\end{array}$ & LE on Mitral Valve \\
\hline 15. & $\begin{array}{l}\text { 2013, Wu et al. } \\
{[16]}\end{array}$ & - & LE on Aortic Valve \\
\hline 16. & $\begin{array}{l}\text { 2014, Veloria et } \\
\text { al. [17] }\end{array}$ & - & LE on Aortic Valve \\
\hline 17. & $\begin{array}{l}\text { 2014, Yacoub et } \\
\text { al. [18] }\end{array}$ & Normal & LE on Aortic Valve \\
\hline 18. & $\begin{array}{l}\text { 2015, Kitchool et } \\
\text { al. [19] }\end{array}$ & Normal & LE on Mitral valve \\
\hline 19. & $\begin{array}{l}\text { 2015, Chu et al. } \\
{[20]}\end{array}$ & Normal & LE on Aortic Valve \\
\hline 20. & $\begin{array}{l}2015 \text {, Villella et } \\
\text { al. [21] }\end{array}$ & $\begin{array}{l}\text { LE on Mitral } \\
\text { Valve }\end{array}$ & - \\
\hline 21. & $\begin{array}{l}\text { 2015, Dumitrascu } \\
\text { et al. [22] }\end{array}$ & Normal & LE on Aortic Valve \\
\hline 22. & $\begin{array}{l}\text { 2015, Davogustto } \\
\text { et al. [23] }\end{array}$ & $\begin{array}{l}\text { LE on Aortic } \\
\text { Valve }\end{array}$ & LE on Aortic Valve \\
\hline 23. & $\begin{array}{l}\text { 2016, Kamran et } \\
\text { al. [24] }\end{array}$ & Normal & LE on Aortic valve \\
\hline 24. & 2016, Jo et al. [25] & - & LE on Aortic valve \\
\hline 25. & 2016, Jo et al. [25] & - & LE on Aortic valve \\
\hline 26. & $\begin{array}{l}\text { 2017, Meireleset } \\
\text { al. [26] }\end{array}$ & - & - \\
\hline 27. & $\begin{array}{l}\text { 2017, Vlacancich } \\
\text { et al. [27] }\end{array}$ & - & LE on Aortic valve \\
\hline
\end{tabular}

Dysarthria/aphasia $51.85 \%$

Hemiparesis/paresis $44.45 \%$

Headache $18.52 \%$

Altered mental status $14.81 \%$

Dizziness $11.11 \%$

Facial droop $7.41 \%$

Blurry vision $7.41 \%$

Photophobia $7.41 \%$

Phonophobia $7.41 \%$

AmaurosisFugax 3.70\%

Falls 3.70\%

Diplopia $3.70 \%$

Table 2: Presenting complaint $(\mathrm{n}=27)$.

Aspirin 30\%

Dual antiplatelet therapy $19 \%$

Anticoagulation 30\%

Valve surgery $30 \%$

Table 4: Management of stroke secondary to LE.

\section{Conclusion}

LE is a rare cause of cardioembolic stroke. When noted on imaging studies it is difficult to conclude if LE is the cause of stroke or just an innocent bystander. As noted in our study LE is associated with high risk of stroke recurrence. TEE is superior to TTE in detection of LE. The study design likely attributes to no mortality not noted in our study and as noted with other causes of cardioembolic stroke, LE may be expected to carry a high mortality rate on follow up. We recommend dual antiplatelet after the first episode of CVA related to LE and an antiplatelet in combination with anticoagulation after the second CVA attributed to LE. Also it is reasonable to offer valve replacement after second CVA related to LE as the recurrence rate of CVA is high. Due to rarity in LE reporting and its management a shared decision making has to be made depending on the clinical status of the patient.

\section{Competing Interests}

The authors declare that they have no competing interests.

\section{Funding}

This work is supported, in part, by the efforts of Dr. Moro O. Salifu M.D., M.P.H., M.B.A., M.A.C.P., Professor and Chairman of Medicine through NIH Grant number S21MD012474.

\section{References}

1. Vital Signs: Recent trends in stroke death rates - United States, 2000-2015 MMWR 2017; 66.

2. Samsa GP, Bian J, Lipscomb J, Matchar DB (1999) Epidemiology of Recurrent Cerebral Infarction: A Medicare Claims-Based Comparison of First and Recurrent Strokes on 2-Year Survival and Cost. Stroke 30: 338-349.

3. Arboix A, Alioc J (2010) Cardioembolic stroke: clinical features, specific cardiac disorders and prognosis. Current cardiology reviews 6: 150-161.

4. Roldan CA, Shively BK, Crawford MH (1997) Valve excrescences: prevalence, evolution and risk for cardioembolism. J Am CollCardiol 30: 1308-1314.

5. Nighoghossian N, Trouillas P, Perinetti M, Barthelet M, Ninet J, et al. (1995) Lambl's excrescence: an uncommon cause of cerebral embolism. Rev Neurol (Paris) 51: 583-585.

6. Voros S, Nanda NC, Thakur AC, Narayan VK, Samal AK, et al. (1999) Lambl's excrescences involving the pulmonary valve detected by transesophageal echocardiography. Echocardiography16: 35-39. 
Citation: Kariyanna PT, Jayarangaiah A, Rednam C, Hegde S, Marmur JD, et al. (2018) Lambl's Excrescences and Stroke: A Scoping Study. Int J Clin Res Trials 3: 127. doi: https://doi.org/10.15344/2456-8007/2018/127

Page 5 of 5

7. Aggarwal A, Leavitt BJ (2003) Giant Lambl's excrescences. New England Journal of Medicine 349: e24.

8. Siles Rubio JR, Ruiz de Castroviejo del Campo J, Tirado Miranda R, Jansen Chaparro S, Pavlovic D (2006) Transient ischemic attack due to Lambl's excrescence. Report of a case and review of the literature. An Med Interna 23. $181-183$

9. Aziz F, Baciewicz Jr FA (2007)Lambl's excrescences: review and recommendations. Tex Heart Inst J 34: 366-368.

10. Wolf RC, Spiess J, Vasic N, Huber R (2007) Valvular strands and ischemic stroke. European Neurology 57: 227-231.

11. Kalavakunta JK, Peddi P, Bantu V, Tokala H, Kodenchery M (2010) Lambl's excrescences: a rare cause of stroke. J Heart Valve Dis 19: 669-670.

12. Raju V Srinivasan M, Padmanaban C, Muthubaskaran V, Abhaichand RK et al. (2011) Double Giant Lambl's Excrescence of aortic valve causing posterior circulation stroke. Indian Journal of Thoracic and Cardiovascular Surgery $27: 36-38$

13. Manolakis C (2011) Lambl Excrescences in a Woman With Recurrent Strokes. Consultant 360 .

14. Liu RZ, Yu SY, Li Y (2012) Migraine-like headache and ischemic strokes in two patients with Lambl's excrescences. Chin Med J 125: 3346-3348.

15. Al-Ansari S, Hindori V, Riezebos RK, Yilmaz A (2013) Multiple Lambl's excrescences with subvalvular extension, a rare cause of cryptogenic stroke: treated by port-access cardiac surgery. BMJ case reports 2013: bcr2013201161.

16. Wu TY, Gerber IL, Roxburgh RH (2013) Thrombo-embolic cerebral infarction secondary to giant Lambl's excrescence. J Clin Neurosci 20: 1632-1634.

17. Veloria EN (2014) Lambl's Excrescence: An Uncommon Cause of Cardioembolic Stroke. Journal of Doctoral Nursing Practice 7: 144

18. Yacoub HA, Walsh AL, Pineda CC (2014) Cardioembolic stroke secondary to Lambl's excrescence on the aortic valve: a case report. J VascInterv Neurol 7: $23-25$

19. Kitchloo K, Lam P, Saxena A, Yoon T, Seneviratne C, et al. (2015) Valvular Strands: A Rare Cause for Stroke in a Young Patient. Chest 148: 268A.

20. Chu A, Aung TT, Sahalon H, Choksi V, Feiz H, et al. (2015) Lambl's excrescence associated with cryptogenic stroke: a case report and literature review. Am Case Rep 16: 876-881.

21. Villella E, Aulivola B (2015) Lambl's Excrescence: Innocent Bystander or Culprit Lesion in Cerebrovascular Embolism? Journal of Vascular Surgery 62: 835 .

22. Dumitrascu O, Tsimerinov E (2015) Recurrent ischemic strokes and headaches originating from Lambl's excrescence. Neurology 84: P2-273.

23. Davogustto G, Fernando RR, Loghin C (2015) Lambl's excrescence migrainous headaches, and "tiger stripes": puzzling findings in one patient. Tex Heart Inst J 42: 70-72.

24. Kamran H, Patel N, Singh G, Pasricha V, Salifu M, et al. (2016) Lambl's excrescences: A case report and review of the literature. Clinical case reports and reviews 2: 486

25. Jo KD, Jang W, Lee MK (2016) Lambl's Excrescences Associated with Ischemic Stroke. Cerebrovascular Diseases 42: 71

26. Meireles VG, Santos VM, Villaça RB, Moraes AC, Watanabe AL, et al. (2017) Lambl's excrescences in a woman with recurrent changes of consciousness. Revista de Medicina e Saúde de Brasília 6: 1.

27. 27. Vlacancich RH, Case BC (2017) Lambl's excrescences-A forgotten cause of cryptogenic strokes? Open J Clin Med Case Rep 3: 1332.

28. Benjamin EJ, Blaha MJ, Chiuve SE, Cushman M, Das SR, et al. (2017) Heart disease and stroke statistics-2017 update: a report from the American Heart Association. Circulation 135: e229-e445.

29. Caplan LR (1999) Clinical Neurocardiology. Marcel Dekker: New York

30. Leary MC, Caplan LR (2007) Cerebrovascular disease and neurologic manifestations of heart disease. Hurst's the Heartd. McGraw-Hill: New York.

31. Lambl VD (1856) Papillareexcrescenzenan der semilunar-klappe der aorta. Wien Med Wochenschr 6: 244-247.
32. Quinson P, de Gevigney G, Boucher F, Delahaye F, Perinetti M, et al. (1996) Fibrous aortic valve tumor (Lambl's excrescence) trapped in the right coronary artery. Apropos of a case. Arch Mal Coeur Vaiss 89: 1419-1123.

33. Lopez-Sanchez E1, Muñoz EF, Aviño Martinez JA, Menezo Rozalen JL (2001) Central retinal artery occlusion as the initial sign of aortic valve papillary fibroelastoma. Am J Ophthalmol 131: 667-669.

34. Fitzgerald D, Gaffney P, Dervan P, Doyle CT, Horgan J, et al. (1982) Giant Lambl's excrescence presenting as a peripheral embolus. Chest 81: 516-517.

35. Nakahira J, Sawai T, Minami T (2014) Pathologic Examination of Lambl's Excrescence. J Cardiothorac Vasc Anesth 28: e3-e4.

36. Rbaibi A, Bonnevie L, Guiraudet O, Godreuil C, Martin D, et al. (2002) Importance of transesophageal echocardiography and computed tomography in the differential diagnosis of a case of papillary fibroelastoma revealed by a neurologic accident. Arch Mal Coeur Vaiss 95: 601-605.

37. Nakahira J, Sawai T, Katsumata T, Imanaka H, Minami T, et al. (2008) Lambl's Excrescence on Aortic Valve Detected by Transesophageal Echocardiography. Anesth Analg 106: 1639-1640.

38. Dumitrascu O, Tsimerinov E (2015) Recurrent Ischemic Strokes and Headaches Originating from Lambl's Excrescences: A Case-Report. Int J Neurol Neurother 2: 019.

39. Kissela BM, Khoury JC, Alwell K, Moomaw CJ, Woo D, et al. (2012) Age at stroke temporal trends in stroke incidence in a large, biracial population. Neurology 79: 1781-1787. 